\title{
COMMUNICATING PESTICIDE CONTAMINATION MESSAGES
}

\author{
Jane Henderson and Kloe Rumsey \\ Cardiff University, Department of Archaeology and Conservation, John Percival Building, Column Road, \\ Cardiff, CF10 3EU, Wales
}

\begin{abstract}
Over the last two decades, an increased understanding of the extent of pesticide contamination of organic collections in museums, particularly natural science and ethnographic collections, has developed. This paper explores the intellectual and emotional responses to messages about pesticide risks in museums and reports on the impact of wording on risk warnings. Six risk phrases using different terminology but intended to represent the same danger of pesticide contamination were evaluated by 103 museum staff. We found that how a message was delivered, the degree of science education of users, and phrases associated with hazards affected how a message was perceived. The delivery of risk warnings and the effective communication of collections-based hazards in museums are essential to responsible collections use, particularly those of scientific (Natural History) and cultural (Ethnographic) importance, where collections are most likely to be contaminated with hazardous substances. The results presented are a first step to understanding how the communication of pesticide risks in museums is understood by users of the collections. By understanding how a message is perceived, we provide advice to museum staff about language use for risk communication projects and management of behaviors.
\end{abstract}

Key words.-Risk, pesticide, label, hazard, perception, dread, risk perception, collection, Slovic.

Associate Editor.-Christine Johnson

\section{INTRODUCTION}

Effective communication is central to the safe use of contaminated collections. This paper questions how safety messages associated with pesticide-contaminated collections are understood. By identifying the relationship between language contained in safety warning messages and the perception of those messages, we offer advice on how to communicate risks such that the message produces an appropriate and effective response. This research aims to open a discussion about how people respond to the communication of hazards from pesticide contaminated collections within museums. An ability to communicate messages that have an appropriate impact on perceptions and safety behavior helps those responsible for collections continue the use of collections for public interaction, research, and education.

There has been an increased interest in pesticide contamination of collections, especially in the areas of ethnographic and natural sciences. The concern extends from communities receiving repatriated material to other users of collections such as conservators, care of collections officers, curators, and volunteers. In recent years, efforts to make people aware of this risk have become more routine with the increase in effective risk management (Cane and Gayle 2012). For a message to be effective, it must offer an understanding of the risk and create a perception that appropriate controls are available.

\section{Pesticides in Museums}

Museum staff have long been aware of pesticide contamination of objects. In recent years, the extent of this contamination has been published alongside concerns for repatriation (Goldberg 1996, Odegaard et al. 2005) and the health implications for users of collections within museums (Krug et al. 2007, Cane and Gayle 2012). The treatment of 
pest-susceptible objects with chemical and heavy metal pesticides, such as arsenic trioxide, mercuric chloride, or DDT, was considered to be part of the routine care of a collection from the 1700s to as recently as the 1980s (Hawks 2001, Odegaard et al. 2005:11-12). The type of pesticide residues present on collections and their manner of application varies enormously, resulting in variation in pesticide concentration on objects and the manner in which individuals are exposed (Hawks 2001, Glastrup 2001, Sirois 2001). The full effects of chronic, long-term exposure to heavy metal and chemical pesticides on the body are unknown, but it is known that exposure can lead to fatal diseases, such as cancer (Kearney 2001). The residue concentration, route of exposure, frequency, or duration of contact with an individual cannot be quantified (Shugar and Sirois 2013), and, thus, there is no governmental standard for cumulative exposure to museum pesticides (Palmer 2001, Cane and Gayle 2012). Projects to record and catalog museum pesticides have been undertaken for many natural science collections, with advice on resultant risks from exposure (Sirois et al. 2007, Charlton et al. 2014). It is likely that most natural science and ethnography collections are contaminated with some form of pesticide. While some museums have undertaken scientific investigations to establish the presence and quantity of contaminants (Marte et al. 2006, Krug et al. 2007, Charlton et al. 2014), it is likely that other museums are less aware of the extent of contamination.

The priority response to a known risk is to mitigate it; yet in many museums, the risk is un-quantified. Where a particular toxin such as arsenic is identified, protocols exist to remove it. This process can require costly and time-consuming conservation work and reduces rather than eliminates the risk. Where historic collections may have been treated, but no survey of residual pesticides has been conducted, the precautionary principle should apply. On this basis, basic safety precautions are critical to reduce the potential for exposure (AMNH n.d.).

\section{Psychology of Risk}

To reduce risks of exposure to hazardous pesticides, the use of pesticide-contaminated collections must be managed effectively. Communication is an essential feature of risk reduction. Understanding the psychological factors involved in the different perception of risk by collection users through the research by Slovic, Fischhoff, and Lichtenstein $(1979,1980)$ could aid the construction of effective risk management messages. Slovic et al. $(1979,1980)$ research the variation in ways that individuals understand and feel about a risk, which culminates in different behaviors and attitudes. To manage health and safety risks effectively it is helpful to "understand the ways in which people think about and respond to risk" (Slovic 2000:221). Slovic's research (2000) explains that the way people perceive risk is not necessarily based on an assessment of measurable consequences, which is the approach favored by technical risk management experts. When considering hazardous events people also have emotional responses related to degrees of unknownness, the potential for harm, and the relationships between benefits and the voluntariness of exposure. Communicating risk is therefore a process that considers both data and emotion. An understanding of risk perception by museum staff cannot simply be described by a technical assessment of the risk; it must also assess the degree of concern about the particular risks that people experience.

\section{Slovic Risk Typology}

Slovic and his colleagues defined the "psychological, social, institutional and cultural factors" that explain how people experience risk, plotting these on a matrix with axis of 
Table 1. Risk characteristics, after Slovic et al. (1979).

Voluntariness of risk

Do people face this risk voluntarily? If some of the risks are voluntarily undertaken and some of them are not, mark an appropriate spot towards the centre of the scale.
Risk assumed voluntarily

Immediacy of effect

To what extent is the risk of death immediate? Or is death likely to occur at some time later?

$\begin{array}{lllllllll}\text { Effect immediate } & 1 & 2 & 3 & 4 & 5 & 6 & 7 & \text { Effect delayed }\end{array}$

Knowledge about risks

To what extent are the risks known precisely by the persons who are exposed to those risks?

$\begin{array}{lllllllllll}\text { Risk level known precisely } & 1 & 2 & 3 & 4 & 5 & 6 & 7 & \text { Risk level not known }\end{array}$

To what extent are the risks known to science?

$\begin{array}{llllllllll}\text { Risk level known precisely } & 1 & 2 & 3 & 4 & 5 & 6 & 7 & \text { Risk level not known }\end{array}$

Control over risk

If you are exposed to the risk, to what extent can you, by personal skill or diligence, avoid death?

$\begin{array}{llllllllll}\text { Personal risk can't be controlled } & 1 & 2 & 3 & 4 & 5 & 6 & 7 & \text { Personal risk can be controlled }\end{array}$

Newness

Is this risk new and novel or old and familiar?

$\begin{array}{lllllllll}\text { New } & 1 & 2 & 3 & 4 & 5 & 6 & 7 & \text { Old }\end{array}$

Chronic/catastrophic

Is this a risk that kills people one at a time (chronic risk) or a risk that kills large numbers of people at once (catastrophic risk)?
Chronic
1
23
45
$6 \quad 7$ Catastrophic

Common/dread

Is this a risk that people have learned to live with and can think about reasonably calmly, or is it one that people have great dread for-on the level of a gut reaction?
Common
$\begin{array}{llll}1 & 2 & 3 & 4\end{array}$

Severity of consequences

When the risk from the activity is realized in the form of a mishap or illness, how likely is it that the consequence will be fatal?

Certain not to be fatal

$\begin{array}{llllllll}1 & 2 & 3 & 4 & 5 & 6 & 7 & \text { Certain to be fatal }\end{array}$

degrees of knownness and dread (2000:xxiii). The research identified and categorized eight characteristics of risk, each of which contribute to how an individual perceives that risk. These characteristics help differentiate an individual's response to the risk of exposure to risks as diverse as coffee, skiing, or pesticides. Most people respond to risks in different ways according to characteristics such as how familiar a risk is or whether exposure to it is voluntary, inevitable, or imposed. Slovic et al. (1979) set a 1-7 scale for each of these eight characteristics (Table 1). This results in a "taxonomy of risk characteristics," which Slovic et al. (1980) utilized in many studies to assess societal responses to hazards. This method of research has achieved significant prominence in the risk management literature.

\section{Aims of Communicating Safety Information}

Within a museum context, to achieve a community of collection users with appropriate behavior and attitudes toward contaminated collections, risks must be communicated with maximum efficiency and result in consistent and predictable understanding and responses. For example, if collection users are not able to think about a risk reasonably calmly (as described on Slovic's common/dread scale), this would prevent a measured consideration of the hazard and may become a barrier to access. Stiff and Mongeau (2003) discuss the use of persuasive messages that arouse "fear by depicting a personally 
Table 2. Risk phrases.

\begin{tabular}{llll}
\hline & \multicolumn{1}{c}{ Origin } & \multicolumn{1}{c}{ Stigmatized word (s) } & Action \\
\hline 1 This object is contaminated with pesticides & Museum warning & Contaminated Pesticides & Passive \\
2 Carcinogenic substance present & Health warning & Carcinogenic & Passive \\
3 Toxic substance present & HSE language & Toxic & Passive \\
4 Toxic by inhalation & HSE language & Toxic & Active \\
5 Arsenic present & Museum warning & Arsenic & Passive \\
6 Arsenic present: The Health & HSE EH40 'Workplace & Exposure Arsenic & Passive \\
and Safety Executive guideline limit & exposure limits' & & \\
of exposure to arsenic is set at & & & \\
$0.1 \mathrm{mg} \mathrm{m}^{-3}$ in an $8 \mathrm{hr}$ period. & & & \\
\hline
\end{tabular}

relevant and significant threat." They conclude that these approaches result in strong but emotionally charged responses that are ineffective in a work context. However, if collection users believe it is likely that they may die immediately as a consequence of exposure (severity), this will make the hazard seem significant and require action. An ability to control a risk is likely to encourage individuals to take safety precautions. In a museum context, the "perfect" message creates a sense that serious consequences would be experienced unless these achievable safety precautions are undertaken.

Familiarity and knowledge of risks make hazards feel manageable in context. The ideal responses to a message would be the consistent reporting of the combination of (1) a perception of high severity, (2) an understanding that there may be a delay in the experience of the effects, (3) a sense of a high level of avoidability, and (4) familiarity and knowledge of the risks with low levels of dread. This would indicate an understanding of the potential risks of handling pesticide-contaminated objects with a calm and measured acceptance of available methods of mitigation.

This study utilizes the framework developed by Slovic and colleagues to assess the perceptions of risks described by hazard warning labels that may be applied to museum collections. A questionnaire was developed with the aim of investigating if different phrasing of risk messages influences perceptions, as measured against Slovic's characteristics, and from this evaluating which messages may be most effective within museums.

\section{Methodology}

The study adopted Slovic's framework to understand the perception and response to a risk based on the wording of the message. We generated six risk warning phrases that describe the same hazard with different words. The design of the risk phrases (RPs) was based on a combination of what might be found on a museum specimen with a subtle change in psychological factors. These phrases included direct quotations from the Health and Safety Executive, quantitative warnings, descriptive text based on real museum practice, language related to social stigma, and passive or active modes of delivery (exposure) (Table 2). To consider psychological variables, words that may create different sensations of dread or stigma (Slovic 2000) were chosen such as "toxic," "carcinogenic," and "contaminated." The way in which a user might contact the pesticide varied between passive and active expressions, such as "toxic substance present" and "toxic by inhalation." Minor variables in the phrases were manipulated to identify critical features of the message. For example, the presence of "carcinogens" could be compared to the presence of "toxic substances" or the impact of adding quantitative data to the arsenic message. 
Table 3. Risk characteristics and range as used in survey.

\begin{tabular}{lcc}
\hline \multicolumn{1}{c}{ Characteristic } & Instigating low risk (1) & Instigating high risk (7) \\
\hline Familiarity & Old & New \\
Immediacy & Immediate & Delayed \\
Knowledge - to individuals & Known & Unknown \\
Knowledge - to science & Known & Unknown \\
Avoidability & Avoidable & Unavoidable \\
Dread & Common & Dread \\
Severity & Not fatal & Fatal \\
\hline
\end{tabular}

Our questionnaire asked respondents to identify if they (1) had a high or low scientific background and understanding, (2) had a conservator or nonconservator role within a museum, (3) were paid staff or a volunteer, and (4) their length of service within the museum sector $(0-5,6-10,11-20$, and $21+$ years $)$. The authors speculated that these variables may reveal different levels of familiarity and fear for the different hazard warning labels. Respondents were asked to offer their subjective response to text on a nominal scale of opinion. Respondents were asked their view on how well known a risk was both to themselves and to science.

\section{Risk Phrases (RPS)}

Respondents were presented with one risk phrase at a time and were not given an opportunity to compare risk phrases. Each phrase represented a distinct scenario. The risk phrases were presented in the same order to all respondents, so some order effect may be in place. The origin of each phrase is shown in Table 2.

\section{Questionnaire}

Respondents were asked to consider hypothetical situations of an object in a museum labeled with a series of risk phrases (Table 2) and asked to rate the characteristics of risk perception using a seven-point scale related to that characteristic (as set out in Table 3). Slovic's (1979) questions related to voluntariness of exposure and catastrophic fatality were removed as the scenario was work based and the hazards presented would never result in catastrophic fatality, respectively (Table 3). For the characteristic "familiarity" aspect, we reversed the presentation of the scale to show it as from old to new in order to align with an otherwise standard presentation within the questionnaire of good (old) to bad (new).

Respondents were contacted using a range of social media. Both curatorial and conservation specific sites produced 160 responses. A few respondents failed to complete the questionnaire, and these were excluded from analysis, which resulted in a total of 103 responses (Table 4). The response rate for volunteers was too small for separate interpretation of their results, so while their responses were considered as part of the general population, they were not investigated as a distinct group.

\section{RESPONSE}

With a response rate of 103 it may be possible to infer valuable information about responses to the risk phrases by those working in museums with such potentially contaminated collections. The questionnaire results are shown as bubble graphs showing the distribution of responses on the 1-7 scale for each of the six risk phrases. 

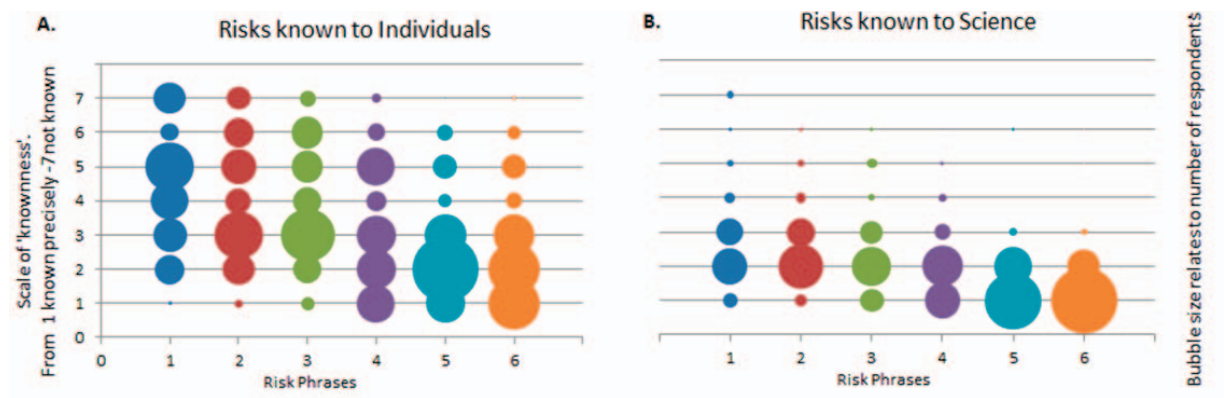

\section{Risk Phases:}

1 Object contaminated with pesticides

2 Carcinogenic substance present

3 Toxic Substance present

4 Toxic by inhalation

5 Arsenic present

6 Arsenic present: The Health and Safety Executive guideline limit of exposure to arsenic is set at $0.1 \mathrm{mg} \cdot \mathrm{m}^{-3}$ in an 8 hour period

Figure 1. Bubble graph showing percentage selection of each score, and indicating the spread of, or concentration of, opinions related to knowledge of risk (a) to individuals and (b) to science against the six risk phrases used in the questionnaire. Respondent's opinions of "knownness" to science are generally more consistent than those of "knownness" to individuals for all risk phrases. Y-axis shows the number of respondents on their perception of knowledge about a risk on a scale from Risk level known precisely to Risk level not known, as Table 1 .

The clusters of opinions highlight trends in perception responses for different questions (Figs. 1-3).

\section{Knowledge of Risk}

Most respondents indicated that they believe risk information is available to science, but there was a far greater distribution as to whether the risk was known or not known to individuals (Fig. 1). Risk phrases 5 and 6 offer a chance to explore if the additional information provided after the statement "Arsenic present" clarifies a sense of how the hazard is understood. The results for the respondent group as a whole show a similar distribution for both phrases, which suggests that the simpler statement in RP5, "Arsenic present," is a more efficient message.

\section{This Object Is Contaminated with Pesticides}

The most straightforward of the phrases in this study, "This object is contaminated with pesticides" (RP1), communicated the hazard simply and might be considered to be the obvious choice of language for a warning label. Low feelings of dread are reported for the risk (Fig. 2c), but this is accompanied by perceptions of immediacy (Fig. 2a), low

Table 4. Summary of respondents and respondent groups.

\begin{tabular}{|c|c|c|c|c|c|}
\hline \multirow[b]{2}{*}{ Total respondents } & \multirow[b]{2}{*}{$\begin{array}{l}\text { Fully complete } \\
\text { responses }\end{array}$} & \multicolumn{2}{|c|}{ Volunteers } & \multicolumn{2}{|c|}{ Paid staff } \\
\hline & & Conservators & Nonconservators & Conservators & Nonconservators \\
\hline 160 & 103 & 11 & 4 & 51 & 37 \\
\hline
\end{tabular}


A.

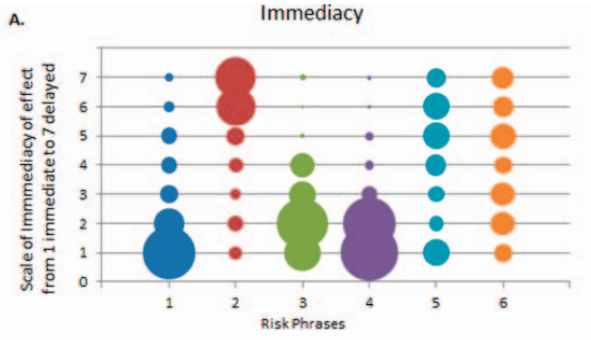

c.

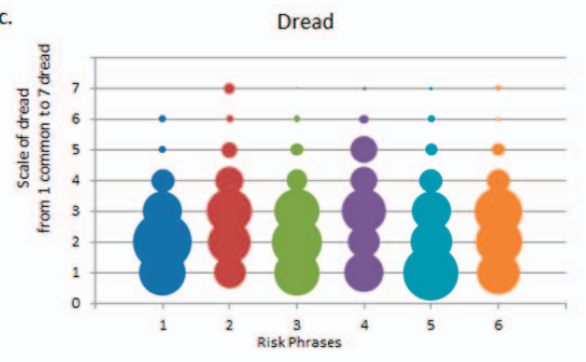

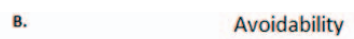

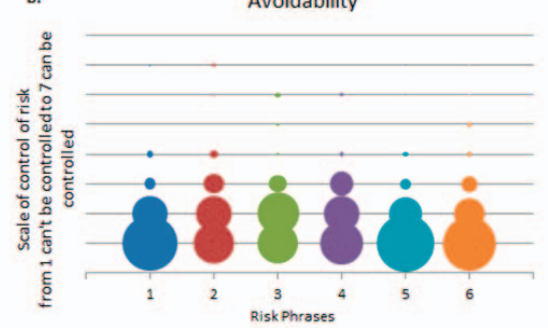

D.

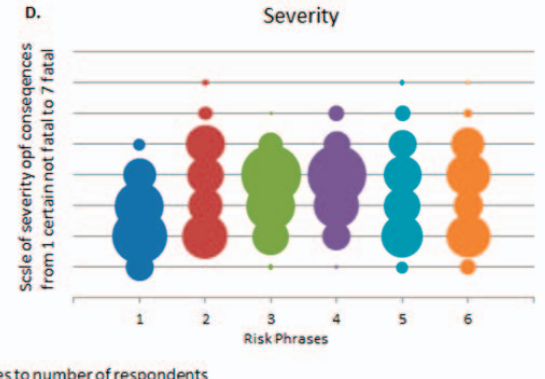

Risk Phases:

1 Object contaminated with pesticides

2 Carcinogenic substance present

3 Toxic Substance present

4 Toxic by inhalation

5 Arsenic present

6 Arsenic present: The Health and Safety Executive guideline limit of exposure to arsenic is set at $0.1 \mathrm{mg} \cdot \mathrm{m}^{-3}$ in an 8 hour period

Figure 2. Bubble graph showing number of respondents selecting each point on a preference scale described in Table 1 for their perception of risk of (a) immediacy, (b) avoidability, (c) dread, and (d) severity.

severity (Fig. 2d), and inconsistency in "knownness" by individuals (Fig. 1). This indicates that the respondents judge the threat to be less severe than for other messages, and they do not have a consistent understanding of the potential consequences. The use of this phrase alone is ineffective as it indicates that while respondents believed such a message indicated an immediate threat, they also perceived the severity to be low and had a divergent range of responses as to how they understand it (knownness). This is not an ideal set of perceptions for a hazard that may be fatal if exposure is cumulative. These findings suggest caution about the use of such a risk warning message.

\section{Active or Passive Exposure}

By investigating a paired set of active and passive phrases, we can examine how the respondents react to the impact of a delivery mechanism rather than the inherent nature of the hazard. The response to the passive phrase, RP3 "Toxic substance present" can be compared to the active phrase, RP4 "Toxic by inhalation." We found that the active phrase "Toxic by inhalation" was reported by some subjects as being more immediate, more known, less avoidable, more dreaded, and slightly more severe than "Toxic substance present." The perceptions of familiarity for both phrases show inconsistency between all respondents (Fig. 3). The phrase "Toxic by inhalation" (RP4) scored more strongly for immediacy (score of 1 for immediacy, $n=38$ ) than "Toxic substance 


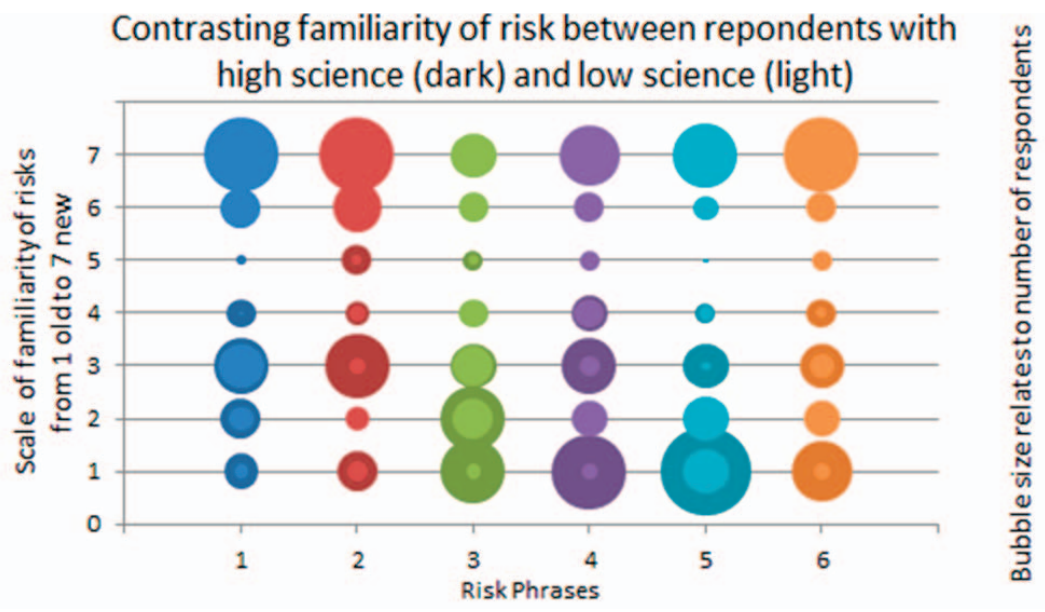

Risk Phases:

1 Object contaminated with pesticides

2 Carcinogenic substance present

3 Toxic Substance present

4 Toxic by inhalation

5 Arsenic present

6 Arsenic present: The Health and Safety Executive guideline limit of exposure to arsenic is set at $0.1 \mathrm{mg} \cdot \mathrm{m}^{-3}$ in an 8 hour period

Figure 3. Bubble graph comparing the number of respondents selecting each point on a preference scale described in Table 1 for their familiarity with a risk (old-new), considering the respondent's level of scientific knowledge. Those respondents with a high level of scientific education shown as darker dots and those with low level science education as lighter dots.

present" (RP3) (score of 1 for immediacy, $n=24$ ) (Fig. 2). This difference suggests that the delivery mechanism "inhalation" has an impact on the perception of how quickly health impacts will be discernible. This result merits further investigation.

"Carcinogenic substance present" (RP2) has a very similar effect to "Toxic by inhalation" (RP4) on respondent perceptions across all of the seven risk characteristics except immediacy. For RP2, 53 respondents offered scores of six or seven for immediacy corresponding with a sense of a delayed response, compared to only six respondents for RP3 and RP4 (Fig. 2). This may reflect a general understanding of the delayed effects of carcinogens, based on a widely understood meaning arising from other health advice encountered in warning messages.

Although responses for "dread" characteristics of the risks (Fig. 2c) are fairly widely spread over lower levels (1-4), it is interesting to note that the use of the word "carcinogenic" (RP2) generated a higher number of highest level dread response. Six individuals rated this as the highest dread risk compared to only $0-3$ such responses for the other five phrases. The term "carcinogenic" is thus a powerful communicator of this aspect of pesticide contamination, but these stronger feelings of dread and the emotional association is undesirable.

"Arsenic present" (RP5) is the phrase considered the most avoidable by individuals (Fig. 2b) and also less dreaded (Fig. 2c); accordingly it is least likely to cause unnecessary levels of anxiety. Perceptions of individuals to the immediacy of "Arsenic present" are 


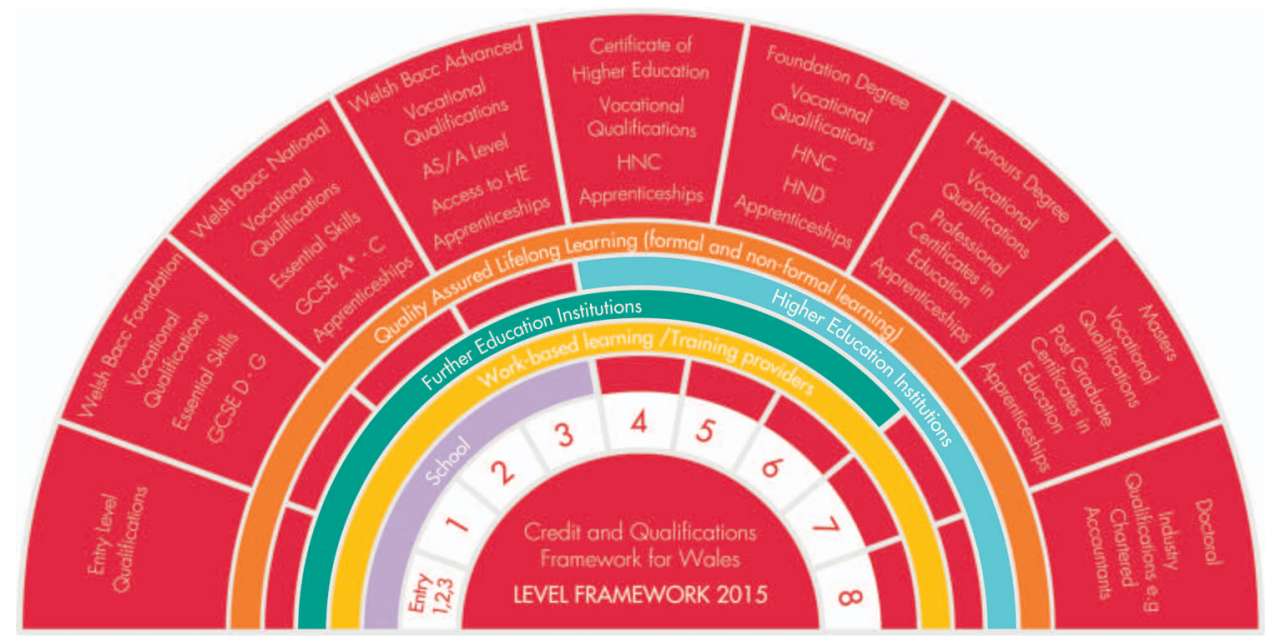

Figure 4. Fan diagram used for survey respondents to indicate their science level, with levels 1-3 describing an individual with "low science" education and 4-8 describing "high science" education (Community Development Workforce Wales 2003).

distributed across the scale showing no consistent understanding of the immediacy of the impact reported (Fig. 2a).

\section{High and Low Science}

We examined the results by respondent subcategories. The most significant distinction between respondent subgroups is the difference between individuals with high and low levels of science knowledge, as measured by the highest level of science qualification. Individuals were asked to self-assess their level of science education using a table provided (Fig. 4). Scores of 1-3 are described as low science, and scores of 4-8 are a high level of science. Individuals having a low level of science offered the broadest range of opinion. The strongest distinction between high and low science respondents was towards the familiarity of risk and the breakdown between these categories is shown in Figure 3. A comparison of the responses to risk phrases 5 and 6 reveals that those who selfidentified as having low levels of science are far more likely to perceive of the risk as new than those who identified themselves as having high science.

This response is not surprising but serves as a reminder of the value of targeted and informative communication that caters to different users. Slovic's research shows that people have a different relationship to risks with low and high familiarity. The public might rate alcohol or fireworks as "high familiarity" and nitrates and polyvinyl chloride as "low familiarity." There is a potential relationship between familiarity and a willingness to expose oneself to a risk. Increased familiarity with risks may also be seen in individuals with more than 21 years of experience working in museums, where high levels of familiarity with the risks were reported. As the length of time in a position increased, so did the reported level of familiarity with the risks. The assessment of knowledge or control of a hazard did not appear to be related to the reported length of experience in the museum. An increase in familiarity without more knowledge may not lead to desirable patterns of safety behavior. 


\section{RISK INFORMATION: RECOMMENDATIONS}

The diverse range of responses regarding risk familiarity may be due to a lack of formal education about pesticides issues in museums. The amount of information that needs to be communicated to individuals is too much for small-scale object labeling. Attempts to do so are likely to result in uncertain and inconsistent responses. To effectively communicate the risks of pesticide residues on collections, museum staffs need simple, sensitive, and explanatory labeling systems such as "Arsenic present." This should be supported with formal educational communication projects to provide individuals with the background information on which to draw when confronted with warning labels. Information on spotting potentially contaminated collections as well as reassuring users on the effectiveness of personal protective equipment will allow museum staff to continue to use collections and collection storage spaces safely while minimizing anxiety. Strategies that employ multiple-warning delivery methods to "present consistent information through mutually reinforcing visual and auditory channels" (Huntley-Fenner 2011) help tackle a desensitization to health warnings. Delivery methods such as meetings, posters, and information boards and using visual cues such as shape and color encourage individuals to observe safety advice. This approach to communication is appropriate for relaying information that is both complex and uncertain, such as the extent and composition of pesticide contamination.

The museum community can approach a consistent perception of the risks from pesticide contaminated museum collections through a range of actions (Fischhoff et al. 2011). This can be undertaken in various measures such as the following:

- Visual assessment of collections to indicate the presence of pesticide contamination and communicating indicators of pesticide presence to museum staff

- Seminars presenting pesticide use, toxicity, routes of exposure to individuals, and health implications

- Provision of PPE and visual reminders of health and safety advice in the form of simple posters with attention to language, shape, and color

- Information packs and appropriate protective equipment provided for new users

- Reinforcement of good safety practice

Users may infer outcomes of a hazard from the means by which they contact it, for example, that inhalation results in immediate effects. The method of exposure is important information; however, the potential for confusion between the consequences of a hazard and the delivery mechanism is not desirable in safety warning messages.

Sensitively presented information about pesticides can communicate the risks without causing alarm or anxiety to individuals. With background information in place contaminated components of collections can be clearly labeled with simple and accessible vocabulary such as "Arsenic present."

\section{Evaluation}

The research of Paul Slovic and colleagues has allowed us to explore his methods, which has relevance to the issue of risk perception within the museum context. Changing only the language elements of scenarios has been valuable in the assessment of the effect of language on perception, and the results obtained in this study are of interest and may suggest lines of fruitful further study. Several aspects in particular would be interesting to explore with a larger population size, for example, the relationship between the description of a delivery mechanism (i.e., inhalation) and the perception of the immediacy 
of impacts, the relationship that a high level of science knowledge and familiarity with risks has on behavior, or the relationship between familiarity and an individual's willingness to be exposed to a hazard. Such questions could be explored individually, although the Slovic risk matrix may not be the most useful research methodology for such a study. Although we are unable to make claims with high levels of certainty due to the scale of our project, the results of this study are consistent with advice found in literature concerning risk warnings (Huntley-Fenner 2011, Stiff and Mongeau 2003).

\section{CONCLUSION}

There is a growing awareness about the presence of pesticide residues on organic museum objects and the potential health risks to collection users. Communication of clear and effective messages is a vital element in the safe management of natural history and ethnographic collections. This study suggests that users do not interpret safety messages consistently. Thus, we suggest that the most effective forms of communication are those that are brief, avoid excessive emotional responses, and use well-recognized words associated with hazard, such as "arsenic." Such simple labels should be supported by the provision of further information whether through training or via an individual's prior experience. Prior experience appears to be a factor in risk perception and should be considered in risk management of the use of pesticide contaminated collections.

\section{ACKNOWLEDGMents}

The authors would like to thank all of the respondents to the questionnaire. The authors are particularly grateful to the conservation staff at the Pitt Rivers Museum for their encouragement in the pursuit of the topic, and the many individuals who offered particular support and interest with our research. The comments from the reviewers and editor of this publication are gratefully acknowledged.

\section{Literature Cited}

AMNH (American Museum of Natural History). No date. Residual Pesticides. http://www.amnh.org/our-research/ natural-science-collections-conservation/general-conservation/health-safety/residual-pesticides (1 July 2015).

Cane, D., and M. Gayle. 2012. Safe handling of museum collections containing arsenic: Report from Birmingham Museums and Art Gallery. ICON News 40:18-20.

Charlton, A., K. Domoney, and J. Uden. 2014. Pesticide residues on the Cook-Voyager Collection as the Pitt Rivers Museum, University of Oxford. In Icom-CC 17th Triennial Conference Melbourne, International Council of Museums, Paris.

Community Development Workforce Wales. 2003. Credit \& Qualification Framework for Wales. http://www. communitydevelopmentworkforcewales.org.uk/getting-qualified/qualification-credit-framework/ (18 September 2014).

Fischhoff, B., N.T. Brewer, and J.S. Downs. 2011. Communicating Risks and Benefits: An Evidence-Based User's Guide. Food and Drug Administration, U.S. Department of Health and Human Services. 242 pp.

Glastrup, J. 2001. The effectiveness of compressed air in the removal of pesticides from ethnographic objects. Pp. 19-22 in The Contamination of Museum Materials and the Repatriation Process for Native California (N. Caldararo, L. Davis, P. Palmer, and J. Waddington, eds.). Proceedings of a Working Conference at San Francisco State University, Washington DC, 102 pp.

Goldberg, L. 1996. A history of pest control measures in the anthropology collections, National Museum of Natural History, Smithsonian Institution. Journal of the American Institute for Conservation 35(1):23-43.

Hawks, C. 2001. Historical Survey of the Sources of Contamination of Ethnographic Materials in Museum Collections. Pp. 2-11 in The Contamination of Museum Materials and the Repatriation Process for Native California (N. Caldararo, L. Davis, P. Palmer, and J. Waddington, eds.). Proceedings of a Working Conference at San Francisco State University, Washington DC, 102 pp.

HSE. 2011. EH40/2005 Workplace Exposure Limits. 2nd ed. Health and Safety Executive HSE Books, HSE London, $74 \mathrm{pp}$. 
Huntley-Fenner, G. 2011. Human factors. Pp. 163-172 in Communicating Risks and Benefits: An Evidence Based Users Guide (B. Fischoff, N.T. Brewer, and J.S. Downs, eds.). Food and Drug Administration, US Department of Health and Human Services, Washington, DC. 242 pp.

Kearney, T.E. 2001. The chemical contamination of repatriated native Californian NAGPRA materials: Principles for risk assessment for acute and chronic health effects. Pp. 44-52 in The Contamination of Museum Materials and the Repatriation Process for Native California (N. Caldararo, L. Davis, P. Palmer, and J. Waddington, eds.). Proceedings of a Working Conference at San Francisco State University, Washington DC, $102 \mathrm{pp}$.

Krug, S., H. Tellow, A. Unger, B. Paz, and S. Simon. 2007. Biocide determination in ethnological collections-A methodological approach. Zeitschrift für Kunsttechnologie und Konservierung 21(2):270-274.

Marte, F., A. Pequignot, and D.W. Von Endt. 2006. Arsenic in taxidermy collections: History, detection and management. Collection Forum 21(1-2):143-150.

Odegaard, N., and A. Sadongei. 2005. Old Poisons, New Problems: A Museum Resource for Managing Contaminated Cultural Materials. AltaMira Press, Walnut Creek, CA. 160 pp.

Palmer, P. T. 2001. A review of analytical methods for the determination of mercury, arsenic and pesticide residues on museum objects. Pp. 25-41 in The Contamination of Museum Materials and the Repatriation Process for Native California (N. Caldararo, L. Davis, P. Palmer, and J. Waddington, eds.). Proceedings of a Working Conference at San Francisco State University, Washington DC, 102 pp.

Shugar, A.N., and P.J. Sirois. 2013. Handheld XRF use in the identification of heavy metal pesticides in ethnographic collections. Pp. 313-348 in Handheld XRF for Art and Archaeology (A.N. Shugar and J.L. Mass, eds.). Studies in Archaeological Sciences 3. Leuven University Press, Leuven, Belgium. 473 pp.

Sirois, P.J. 2001. The analysis of museum objects for the presence of arsenic and mercury-Non-destructive analysis and sample analysis. Pp. 65-75 in The Contamination of Museum Materials and the Repatriation Process for Native California (N. Caldararo, L. Davis, P. Palmer, and J. Waddington, eds.). Proceedings of a Working Conference at San Francisco State University, Washington DC, 102 pages.

Sirois, P.J., J.S. Johnson, J.A. Shugar, J. Poulin, and O. Madden. 2007. Pesticide contamination: Working together to find a common solution. Pp. 175-187 in Preserving Aboriginal Heritage: Technical and Traditional Approaches (C. Dignard, K. Helwig, J. Mason, K. Nanowin, and T. Stone, eds.). Canadian Conservation Institute, Ottawa, Ontario, Canada. 406 pp.

Slovic, P. 2000. The Perception of Risk. Earthscan, London, United Kingdom. 473 pp.

Slovic, P., B. Fischhoff, and S. Lichtenstein. 1979. Rating the risks. Environment 21:3, 14-20, and 36-39.

Slovic, P., B. Fischhoff, and S. Lichtenstein. 1980. Facts and fears: Understanding perceived risk. Pp. 181-216 in Societal Risk Assessment: How Safe is Enough? (R.C. Schwing and W.A. Albers, eds.). Plenum Press, New York. 364 pp.

Stiff, J.B., and P.A. Mongeau. 2003. Persuasive communication. Guilford Press, New York. 351 pp. 